\title{
Pointing to others: How the target gender influences pointing performance
}

Laurent Cleret de Langavant ${ }^{\mathrm{a}, \mathrm{b}, \mathrm{c}, \mathrm{d}}$, Charlotte Jacquemot ${ }^{\mathrm{a}, \mathrm{b}, \mathrm{c}}$, Virginie Cruveiller ${ }^{\mathrm{a}, \mathrm{b}}$, Emmanuel Dupoux ${ }^{\mathrm{c}, \mathrm{e}}$ and Anne-Catherine Bachoud-Lévi ${ }^{\mathrm{a}, \mathrm{b}, \mathrm{c}, \mathrm{d}}$

AQ1 ${ }^{a}$ INSERM U955 Equipe E01, Neuropsychologie Interventionnelle, Créteil, France; baculté de Médecine, Université Paris Est, Créteil, France;

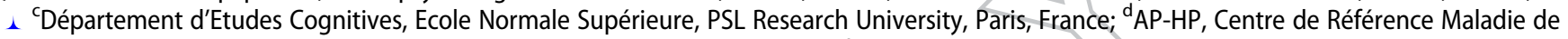

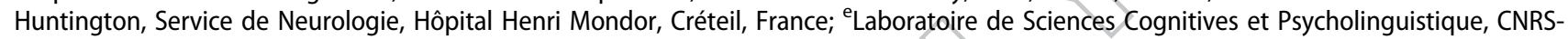
EHESS-ENS, Paris, France

ABSTRACT

Pointing is a communicative gesture that allows individuals to share information about surrounding objects with other humans. Patients with heterotopagnosia are specifically impaired in pointing to other humans' body parts but not in pointing to themselves or to objects. Here, we describe a female patient with heterotopagnosia who was more accurate in pointing to men's body parts than to women's body parts. We replicated this gender effect in healthy participants with faster reaction times for pointing to men's body parts than to women's body parts. We discuss the role of gender stereotypes in explaining why it is more difficult to point to women than to men.
ARTICLE HISTORY

Received 23 November 2015

Revised 27 June 2016

Accepted 29 June 2016

KEYWORDS

Gender; heterotopagnosia; pointing; social interaction; stereotype

\section{Introduction}

\section{Pointing is a social gesture that allows individuals to} communicate with another person about an object or an event. This fundamental skill is observed worldwide in humans, and it is acquired by infants before they can speak, marking a critical step in the development of their social cognition (Charman, 2003; Kita, 2003; Tomasello, Carpenter, Call, Behne, \& Moll, 2005). This gesture is regulated by social norms: Whereas pointing to objects is allowed, pointing to somebody else is often inappropriate or even offensive (Tallis, 2010).

An acquired deficit of pointing, named heterotopagnosia, was discovered in adults after a left posterior parietal lesion (Degos, Bachoud-Lévi, Ergis, Pétrissans, \& Cesaro, 1997). Heterotopagnosic patients fail to point to the body parts of another person, but they can point to objects and to their own body parts (Auclair, Noulhiane, Raibaut, \& Amarenco, 2009; Cleret de Langavant, Trinkler, Cesaro, \& BachoudLevi, 2009; Degos \& Bachoud-Lévi, 1998; Degos et al., 1997; Felician, Ceccaldi, Didic, Thinus-Blanc, \& Poncet, 2003). Strikingly, when asked to point to objects located on another person's body, heterotopagnosic patients perform correctly. In addition, patients typically do not exhibit deficits for grasping or touching another person's body parts. They can touch the very same body parts they failed to point to, ruling out a disorder for localizing body parts or a disorder for making gestures towards others' body parts (Cleret de Langavant et al., 2009).

Despite its complexity, heterotopagnosia not only offers the opportunity to better understand the mechanisms of pointing but also reveals that the human brain distinguishes between different types to pointing targets: humans and objects. Interestingly, patients' accuracy increases when pointing at body parts from figurative representations of the human body (drawings, photographs, dolls, videos) in comparison to body parts of real people (Cleret de Langavant et al., 2009; Felician et al., 2003). These observations suggest that rather than the human body itself, the mental representation of the human body influences pointing performance in heterotopagnosia.

In addition to being differentially impaired in heterotopagnosic patients, objects and human body parts are also processed differently in healthy participants. Indeed, Cleret de Langavant and collaborators (Cleret de Langavant et al., 2012) asked healthy participants to point to two types of targets located on other people's body parts (e...g., neck) and objects (ę.g., necklace). They found faster reaction times for pointing to

CONTACT Charlotte Jacquemot charlotte.jacquemot@ens.fr

(c) 2016 Informa UK Limited, trading as Taylor \& Francis Group 
objects than for pointing to body parts. In a control experiment, the reaction time difference between body parts and objects disappeared when a mannequin replaced the real person's body. This suggests that independently of the location of the target, its nature - human or object - influences the pointing gesture. Human body parts seem to endow a specific status that makes them more difficult to point at. Noteworthy, at the neural level, pointing to others' body parts, but not pointing to objects, recruits a small area of the left posterior intra parietal sulcus (Cleret de Langavant et al., 2012), the same area usually lesioned in heterotopagnosia (Auclair et al., 2009; Cleret de Langavant et al., 2009; Degos et al., 1997; Felician et al., 2003).

When pointing at something, the target is of essence an object of interest (Cleret de Langavant et al., 2009; Degos \& Bachoud-Lévi, 1998). Experimental data from healthy participants show that processing a human body part as a pointing target is cognitively more costly than processing an object as a target, even if the location is exactly the same (Cleret de Langavant et al., 2012). A major difference between objects and humans relies on the fact that one can interact socially, and exchange and communicate with another human, whereas communication with objects is not possible. To explain behavioural and neuronal differences between objects and human body parts, it has been proposed that pointing involves implicitly processing the target as an object deprived of communicative abilities ${ }^{1}$ - whether it is a communicative entity or not (Cleret de Langavant et al., 2009; Degos \& Bachoud-Lévi, 1998). Experimental data with the mannequin body supports this proposal: Since this body is already an object, the difference between objects and body parts vanishes. The process of considering a human as a non-communicative object is impaired in heterotopagnosia. When body parts belong to a real person, who counts as a potential communicative person, heterotopagnosic patients fail to process them as objects, leading to a deficit in pointing to human body parts. ${ }^{2}$ However, when body parts belong to a figurative body (drawing, doll, etc.) - that is, something already processed as an object - patients' accuracy improves. In addition, when heterotopagnosic patients are told to consider another person as a doll and no longer as a person to communicate with, their pointing performance to others' body parts dramatically improves
(Cleret de Langavant et al., 2009). This proposal also explains why pointing is often considered to be rude or offensive in many cultures when directed at other humans. Finally, heterotopagnosic patients are not impaired in making other gestures towards humans, such as touching body parts. However, contrary to pointing, interpersonal touch does not require processing the target of touching as an object, thus explaining why pointing and touching performance differs (Gallace \& Spence, 2010).

In the present paper, we report the case of a female patient, F.A.R. with heterotopagnosia: She showed impaired performance when pointing to others' body parts (e.g., neck) but perfect performance when pointing to objects (e.g., necklace). Unexpectedly, F.A.R.'s performance on pointing to body parts was modulated by the gender of the target. She was severely impaired for pointing to female body parts, whereas she performed better when pointing to male body parts. In order to assess whether this unforeseen profile was specific to this patient or reflected a general bias toward female body parts, we tested healthy participants in a pointing paradigm. We found that reaction times for pointing to women's body parts were longer than those for pointing to men's body parts, regardless of the participant's gender. We interpret these results as in line with recent findings on gender differences (Ellis, 2011).

\section{Case report}

\section{Method}

The patient F.A.R. was an heterotopagnosic 82-yearold woman with logopenic variant of primary progressive aphasia (Gorno-Tempini et al., 2008). A neuropsychological assessment showed that she suffered from severe limitations in language production and executive functions, leading to low scores in general cognitive efficiency (Table 1). Nonetheless, F.A.R. was able to understand and execute simple orders. All pointing trials were video-recorded. Only the first gesture achieved by F.A.R. after each instruction was analysed. T1-weighted brain magnetic resonance imaging (MRI) demonstrated focal atrophy in left perisylvian and left posterior parietal regions, including the left posterior intra parietal sulcus region (Figure 1). F.A.R.'s informed consent was obtained prior to the study. The study was conducted 
AQ12AQ11 Table 1. F.A.R.'s neuropsychological assessment.

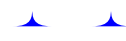

205

\begin{tabular}{|c|c|c|}
\hline \multirow[b]{2}{*}{ Neuropsychological assessment } & \multicolumn{2}{|c|}{ Score } \\
\hline & F.A.R. & $\begin{array}{l}\text { Maximum } \\
\text { possible }\end{array}$ \\
\hline \multicolumn{3}{|l|}{ Global efficiency } \\
\hline Mini Mental Status (Folstein, Folstein, \& McHugh) & 13 & 30 \\
\hline Dementia Rating Scale (Mattis, 1976) & 77 & 144 \\
\hline \multicolumn{3}{|l|}{ Language } \\
\hline $\begin{array}{l}\text { Boston Naming Test (short version) (Goodglass \& } \\
\text { Kaplan, 1983) }\end{array}$ & 9 & 15 \\
\hline $\begin{array}{l}\text { Colored Image Naming (Snodgrass \& Vanderwart, } \\
\text { 1980) }\end{array}$ & 64 & 172 \\
\hline Black \& White Image Naming (Deloche et al., 1996) & 35 & 80 \\
\hline $\begin{array}{l}\text { Comprehension Token Test (De Renzi \& Faglioni, } \\
\text { 1987) }\end{array}$ & 23 & 36 \\
\hline \multicolumn{3}{|l|}{ Semantics } \\
\hline $\begin{array}{l}\text { Functional Image Matching (Agniel, Joanette, } \\
\text { Doyon, \& Duchein, 1993) }\end{array}$ & 8 & 10 \\
\hline Categorical Image Matching (Agniel et al., 1993) & 9 & 10 \\
\hline $\begin{array}{l}\text { Functional Attributes-Artefacts Matching } \\
\text { (Jacquemot, Dupoux, Robotham, \& Bachoud-Levi, } \\
\text { 2012) }\end{array}$ & 20 & 20 \\
\hline $\begin{array}{l}\text { Functional Attributes-Living Things (Jacquemot } \\
\text { et al., 2012) }\end{array}$ & 16 & 20 \\
\hline \multicolumn{3}{|l|}{ Visuo-perception } \\
\hline Line Drawings Identificat & & - \\
\hline $\begin{array}{l}\text { Entangled Drawings Identification (Agniel et al., } \\
\text { 1993) }\end{array}$ & & 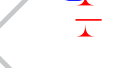 \\
\hline \multicolumn{3}{|l|}{ Gestures } \\
\hline Symbolic Gestures & 4 & 6 \\
\hline Pantomimes & 7 & 10 \\
\hline Posture Imitation & 7 & 10 \\
\hline $\begin{array}{l}\text { Visuo-Construction (Figu } \\
\text { 1988) }\end{array}$ & 11 & 12 \\
\hline $\begin{array}{l}\text { 1988) } \\
\text { Drawings (human, }\end{array}$ & 2 & 6 \\
\hline flower) & & \\
\hline $\begin{array}{l}\text { Drawings Copy (huma } \\
\text { flower) }\end{array}$ & 5 & 6 \\
\hline \multicolumn{3}{|l|}{ Executive functions } \\
\hline Trail Making Test A (Reitan, 1955) & $25(85)$ & $25(-)$ \\
\hline Trail Making Test B (Reitan, 1955) & failed & $25 \stackrel{(H)}{\leftrightarrow}$ \\
\hline Graphic Series (Luria, 1965) & correct & 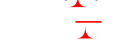 \\
\hline Gesture Series (Luria, 1965) & correct & a \\
\hline $\begin{array}{l}\text { Frontal Assessment Battery (Dubois, Slachevsky, } \\
\text { Litvan, \& Pillon, 2000) }\end{array}$ & 7 & 18 \\
\hline \multicolumn{3}{|l|}{ Verbal fluencies } \\
\hline Categorical Fluencies: Animals (1 min) & 3 & - \\
\hline Literal Fluencies: Letters $\mathrm{M} / \mathrm{S}$ (1 min) & $1 / 3$ & $-1 \frac{1}{-}$ \\
\hline \multicolumn{3}{|l|}{ Attention and memory } \\
\hline $\begin{array}{l}\text { Verbal Digit Span: Forward/Backward (Wechsler, } \\
\text { 1981) }\end{array}$ & $5 / 3$ & \\
\hline $\begin{array}{l}\text { Free and Cued Recall Five Words Test (Dubois, } \\
\text { Touchon, Ousset, Vellas, \& Michel, 2002) }\end{array}$ & 9 & 10 \\
\hline $\begin{array}{l}\text { Image Recognition (DMS 48) (Barbeau et al., 2004): } \\
\text { Set } 1 \text {. }\end{array}$ & 47 & 48 \\
\hline
\end{tabular}

in agreement with recommendations of the local ethics committee.

Test 1: Pointing to the experimenter's body part F.A.R. was tested with the usual setting for assessing heterotopagnosia (Cleret de Langavant et al., 2009). She sat in a quiet room facing the experimenter and was asked to point to objects $(N=20)$ and to body parts. The objects were located in the room $(N=10$, e.g., television), on F.A.R.'s body ( $N=5$, e.g., watch), or on the experimenter's body $(N=5)$. The body parts either belonged to F.A.R. $(N=20)$ or to the experimenter ( $N=20$; nose, forehead, left and right cheek, chin, left and right ear, neck, left and right shoulder, left and right wrist, left and right hand, left and right elbow, left and right knee, left and right foot; Figure 2a). Verbal instructions were provided by the experimenter (e.g." "Show me your nose", in French, "Montrez-moi votre nez", or "Show me my nose", "Montrez-moi mon nez"). In the first part of the test the experimenter was a man, and in the second part the experimenter was a woman ( $M-W, M$ for man and W for woman). Both experimenters wore the same clothes (doctor's coat). Overall, there were 20 pointing gestures directed to objects, 40 to F.A.R.'s own body parts, 20 to the female experimenter's body parts, and 20 to the male experimenter's body parts.

\section{Test 2: Pointing to a third person's body parts}

In Test 1, the experimenter was both the addressee of the pointing - that is, the person F.A.R. was pointing for ${ }_{-}-$and the target of the pointing. This setting Cleret de Langavant et al., 2011), we ran a second test in which the target was a third person different from the experimenter. The patient and the target person were facing each other, and the addressee (the experimenter) was seated next to the patient (Figure 2b). Targets were restricted to body parts. Instructions were as follows: "Show me your nose", or "Show me his/her nose". Three women and three men were alternatively targets of the pointing task in three sessions with the following order, $\mathrm{W}_{-} \mathrm{M}, \mathrm{M}_{-}$ $\mathrm{W}, \mathrm{W}-\mathrm{M}$. The male and female targets wore identical clothes (a doctor's coat), and they were asked to not make any gestures or movements, nor to speak, and to have a neutral facial expression. For each target, F.A.R. was asked to make 20 gestures directed to herself and 20 gestures directed to the other person. Overall, there were 120 trials directed to F.A.R.'s body parts: 60 directed to women's body parts and 60 directed to men's body parts.

Test 3: Grasping the experimenter's body parts The apparatus is identical to that in Test 1 (Figure 2a) except that F.A.R. was required to grasp body parts instead of pointing to them. She was required to grasp body parts located either on herself $(n=20)$ or being potentially confusing for the patient (see, a woman. 


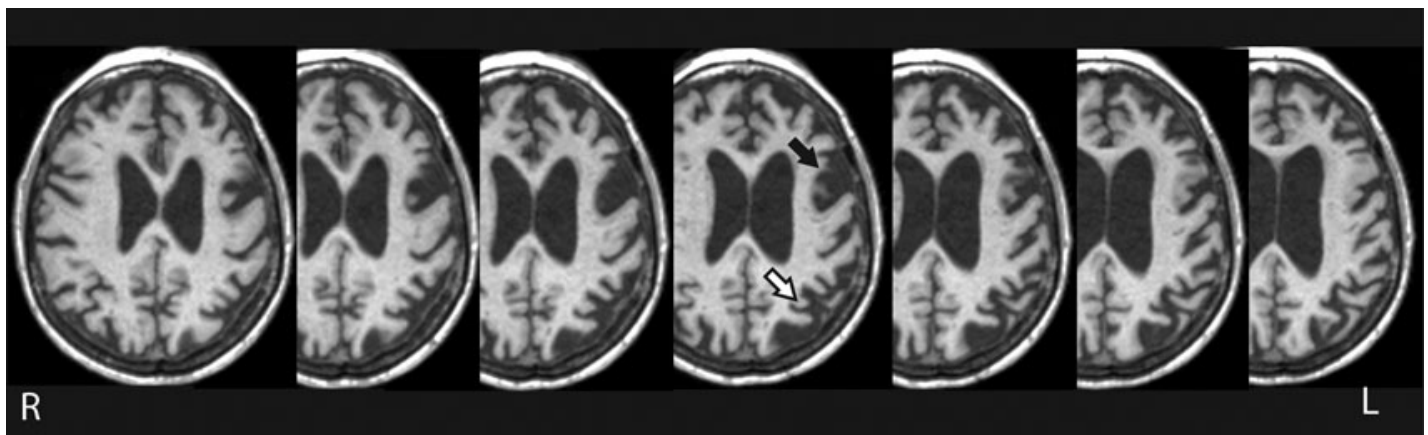

Figure 1. Transverse axial slides from T1-weighted magnetic resonance imaging (MRI) of E.A.R. showing severe atrophy around the left intra parietal sulcus (white arrow) and in the left dorso-lateral frontal cortex (black arrow). L: left; R: right.

\section{Results}

Test 1: Pointing to the experimenter's body part F.A.R. made no errors in pointing to objects $(0 / 20$ errors), regardless of whether they were located in the room, on F.A.R.'s body, or on experimenter's body. Regarding body parts, F.A.R.'s performance was better in pointing to herself (1/40 errors) than to others $\left(14 / 40\right.$ errors), Fischer $X^{2}(1)=11.8, p<10^{-3}$, showing the typical pattern of heterotopagnosia. For others, F.A.R. performance was poorer when pointing

\section{A Pointing participant}
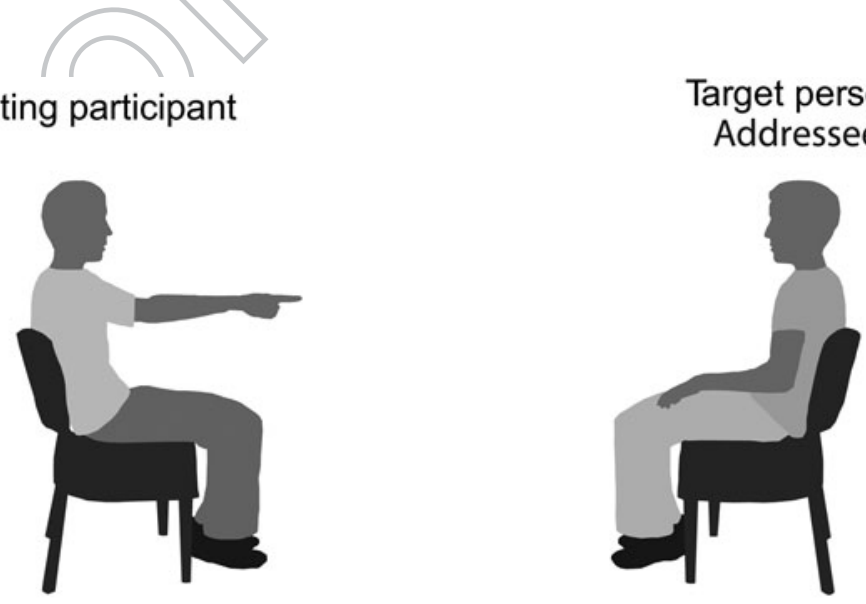

B

\section{Addressee}

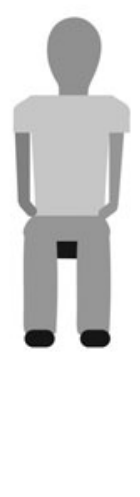

Target person

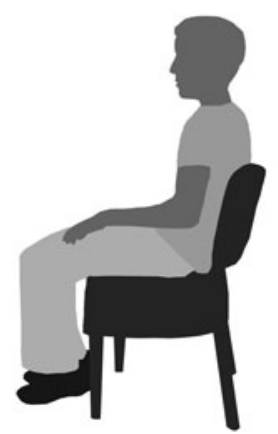

Figure 2. Testing apparatus. (a) The patient and the experimenter/addressee are facing each other. (b) The pointing participant (patient or healthy participant) and the target person are facing each other. The addressee sits on the side of the participant. 
to the woman's body parts than to the man's (female vs. male target: $11 / 20$ errors and $3 / 20$ errors, respectively), Fischer $X^{2}(1)=5.4, \quad p=.02$. F.A.R. showed similar performance for pointing to her body parts and to the man's body parts (self vs. male target: $0 /$ 20 errors and $3 / 20$ errors, respectively), Fischer $x^{2}(1)$ $=0.2, p=.5$, whereas she was better at pointing to her body parts than to the woman's body parts (self vs. female target: $1 / 20$ error and $11 / 20$ errors, respectively), Fischer $X^{2}(1)=9.6, p=.002$. Errors were mostly self-referential errors, meaning that she was pointing to her own body instead of that of the experimenter. Self-referential errors were made in a similar proportion when facing the man or when facing the woman $(3 / 3$ and $9 / 11$, respectively; $p=1)$.

\section{Test 2: Pointing to a third person's body parts}

F.A.R. performed better in pointing to her own body parts than to the other person's body parts $(8 / 120$ errors and 51/120 errors, respectively) Fischer $X^{2}(1)$ $=39.6, p<10^{-3}$. When pointing to herself, she was equally accurate when facing a man or a woman (5/60 errors and 3/60 errors, respectively), Fischer $X^{2}(1)=0.13, p=.7$. When pointing to others, she made more errors when pointing to women's body parts $(37 / 60$ errors) than when pointing to men's body parts (14/60 errors), Fischer $X^{2}(1)=16.5, p<10^{-3}$. (Figure 3). Errors were mostly self-referential, and of a similar proportion when facing men versus when facing women (respectively, 13/14 and 33/37, $p=1$ ).

\section{Test 3: Grasping the experimenter's body parts} F.A.R.'s performance for grasping body parts of another woman (5/20 errors) was similar to that for

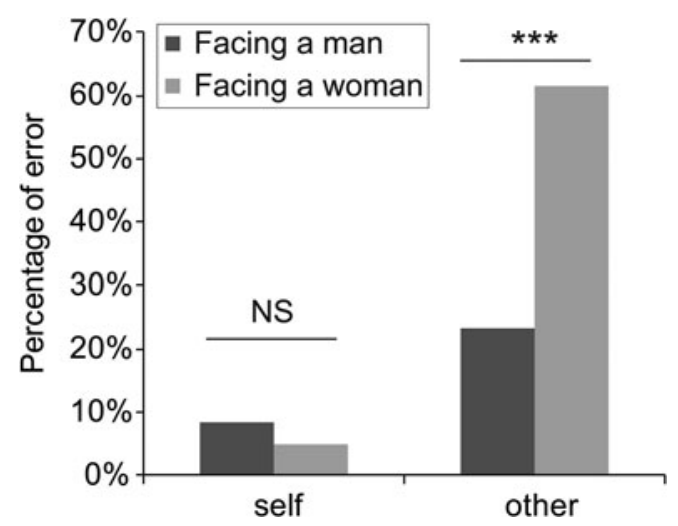

Figure 3. F.A.R.'s mean error rates. NS: non-significant. ${ }^{* * *} p_{\perp}<.001$. grasping her own body parts (3/20 errors), Fischer $X^{2}(1)=0.016, p=7$. F.A.R.'s performance for grasping another woman's body parts were higher than for pointing to another woman's body parts $(37 / 60$ errors from previous experiment); Fischer $X^{2}(1)=$ $11.26, p<10^{-3}$

\section{Pointing to somebody: Healthy participants'} data

F.A.R. showed better performance for pointing to body parts of men than for pointing to those of women. In order to test whether F.A.R.'s deficit emerged due to gender similarity between her and the target or due to a general difficulty for pointing to women's body parts, we assessed how the gender of the target would influence pointing in healthy participants of both sexes.

\section{Method}

\section{Participants}

Sixteen healthy participants ( 8 women, mean age: 33.8 years \pm 17 , mean education level: 15.8 years \pm 1.7 after primary school) were tested. They were all righthanded, and none of them had a history of neurological disease. Participants' informed consent was obtained prior to the study. The study was conducted in agreement with recommendations of the ethics committee.

\section{Apparatus}

The experimental setting was similar to that in Test 2. Three people were involved: a participant, an addressee, and a target person. The participant and the target person were facing each other, and the addressee was seated next to the participant (Figure 2B). For each participant, in half of the trials, the target was a woman; in the other half, the target was a man. The order of presentation of each gender ( $\mathrm{W}-\mathrm{M}$ or $\mathrm{M}-\mathrm{W})$ was counterbalanced across the participants. The male and female targets were different for each participant. They were asked to not make any gestures or movements, nor to speak, and to have a neutral facial expression. Both the addressee and the target person wore identical clothes, and the name they were attributed (Gilles, Lise, Luc, or Maud) was written on a white T-shirt they wore. The instructions were delivered through 
headphones to the participant and provided the name of the addressee, the body part, and the name of the target person (e.g., "Show Gilles the nose of Lise"). After a participant's gesture, the addressee named the pointed-to body part. The pointing gesture was randomly directed to the self $(N=40)$ and to the target person $(N=40)$. In addition, in 20 filler trials the pointing was directed toward the addressee ("Show Gilles the nose of Gilles"). The participant pressed a response button while awaiting the instructions and released it when pointing (Cleret de Langavant et al., 2012). The reaction times were recorded from the onset of the name of the target person until the response button was released. The experiment ran under Expe software (Pallier, Dupoux, \& Jeannin, 1997) allowing for a temporal resolution of $1 \mathrm{~ms}$.

\section{Results}

An analysis of variance (ANOVA) was conducted by participants with reaction time as the dependent variable. We defined two within-subject factors, namely whom (self vs. other) and target gender (male vs. female) and one between-subjects factor, namely participant gender (male vs. female). Filler trials were excluded from the analysis.

Participants made no errors in the pointing task. Pointing to the self was faster than pointing to another person's body (self: $542 \mathrm{~ms}, S E=22 \mathrm{~ms}$ vs. other: $686 \mathrm{~ms}, S E=41 \mathrm{~ms}), F(1,14)=45.3, p<10^{-3}$. There was no main effect of the participant gender, $F(1,14)=0.9, p>.1$, nor a main effect of the target gender, $F(1,14)=2.7, p>.1$. However, an interaction was observed between the factors whom and gender target, $F(1,14)=12.8, p=.003$ (Figure 4). When asked to point to another person, participants pointed more rapidly toward men than toward women $(663 \mathrm{~ms}, S E=38 \mathrm{~ms}$, and $709 \mathrm{~ms}, S E=46 \mathrm{~ms}$, respectively) $, F(1,14)=5.3, p=.036$, regardless of their own gender, $F(1,14)=0.9, p=.34$, and with no interaction between the factors participant gender and target gender, $F(1,14)=0.01, p=.9$. We further compared separately RTs of male and female participants when pointing at men's and women's body parts with a post hoc test. Results show that both female participants and male participants were slower at pointing to women's body parts than to men's body parts (female participants: $747 \mathrm{~ms}$,

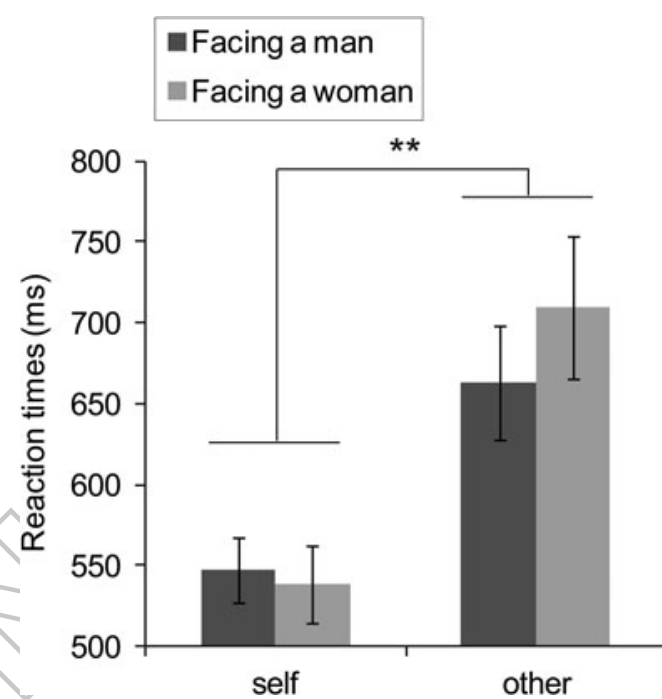

Figure 4. Healthy participants' reaction times (ms; $M \pm S E$ ). ${ }^{* *} p_{1}<.01$.

$S E=77 \mathrm{~ms}$, and $714 \mathrm{~ms}$, $S E=62 \mathrm{~ms}$, respectively, least significant difference, LSD, Fisher test, $p=.019$; male participants: $673 \mathrm{~ms}, S E=51 \mathrm{~ms}$, and $623 \mathrm{~ms}$, $S E=44 \mathrm{~ms}$, respectively, LSD Fisher test, $p=.011$ ).

\section{Discussion}

We report the case study of a female patient, F.A.R., showing the typical pattern of heterotopagnosia. F.A.R. was specifically impaired in pointing to others' body parts whereas she accurately pointed to objects and to herself. F.A.R.'s brain atrophy included the left posterior intra parietal sulcus region (Figure 1), which is consistently found to be lesioned in heterotopagnosic patients (Auclair et al., 2009; Cleret de Langavant et al., 2009; Degos et al., 1997; Felician et al., 2003). Surprisingly, F.A.R. was more impaired in pointing to women's body parts than to men's, suggesting that pointing to women is more difficult than pointing to men. We found a similar pattern with healthy participants. Whatever their gender, they displayed longer reaction times when pointing to women's body parts than when pointing to men's body parts. Healthy participants' results suggest that pointing to another woman's body is cognitively more demanding than pointing to another man's body.

The patient's deficit cannot be explained by a language impairment or dementia. F.A.R. was flawless in pointing to objects and showed good performance in pointing to herself, indicating that despite her 
cognitive deficits, she understood the instructions well. F.A.R.'s low performance in pointing to women cannot be explained by the misunderstanding of possessive adjectives "your" and "my" because she performed better when pointing to men and to objects located on the experimenter. She was also able to grasp the female body parts that she could not point to, adding evidence that F.A.R. correctly understood the name of the body parts and was able to perform a gesture directed towards others.

Several reasons can explain why this gender effect has never been reported in previous studies. First, in previous heterotopagnosia literature, patients were severely impaired, and floor effects could have masked any gender effects (Auclair et al., 2009; Cleret de Langavant et al., 2009; Degos et al., 1997; Felician et al., 2003). F.A.R. displayed a moderately severe heterotopagnosia, allowing us to compare F.A.R.'s performance towards women's body parts and men's body parts. Secondly, the diagnosis of such a form of gender-specific heterotopagnosia requires that two experimenters of different genders consequently test the patient. A male experimenter would have missed the diagnosis of heterotopagnosia in F.A.R.

F.A.R. was more impaired in pointing to women's body parts than to men's body parts (Tests 1 and 2). We replicated this gender effect with healthy participants as well. This difficulty of pointing to women can be explained using the interpretation frame of cultural taboos, politeness, or even prudishness. However, a cultural taboo or prudishness can hardly account for F.A.R.'s preserved ability to grasp another woman's body parts, the same body parts as those she was unable to point to (Test 3). It is unlikely that F.A.R. did not dare point to women whereas she did dare to grasp body parts. An alternative explanation of F.A.R.'s difficulties with female targets is related to the gender similarity between F.A.R. and female targets. Indeed, in heterotopagnosia, the patient's typical error is to point to their own body part rather that the other person's body part. F.A.R. could be more inclined to make self-referential errors when pointing to somebody of the same gender. However, this hypothesis is not supported by F.A.R.'s self-referential data: The proportion of self-referential errors did not differ when pointing to men versus women (Test 1). This gender similarity hypothesis is not supported by the healthy participants' data either. Indeed, according to this hypothesis, women should be slower for pointing to female targets and men slower for pointing to male targets. This was not the case: Both male and female participants were slower at pointing to women than to men.

Overall, F.A.R.'s accuracy and healthy participants' reaction times show that it is more difficult to point to body parts of women than to those of men. This effect cannot solely be explained by a cultural taboo regarding female bodies, nor by a gender similarity effect. There is a lot of evidence of differences between men and women, notably regarding their social behaviour (for a review see, Ellis, 2011). Women show greater socializing behaviour than men and demonstrate higher performance in communicative tasks (Baron-Cohen, 2005; Kret \& De Gelder, 2012). They also are more expressive than men (Wood \& Eagly, 2002), as well as more sensitive to facial emotions (Montagne, Kessels, Frigerio, de Haan, \& Perrett, 2005) and social intentions, such as friendship or sexual interest (Farris, Treat, Viken, \& McFall, 2008). Women's brain responses to social interactive situations (Pavlova, 2009) and affective stimuli (Hofer et al., 2006; Proverbio, Adorni, Zani, \& Trestianu, 2009; Singer et al., 2006) are stronger than men's.

These experimental observations support the common idea that women are in general more socially engaged than men and can give rise to gender stereotypes. Gender stereotypes correspond to expectations about whether a person's characteristic is more typical for men or women (Unger \& Crawford, 1993). These expectations impact social judgments in many different social situations (Brody \& Hall, 2000; Johnson \& Tassinary, 2007) and professional situations (Heilman, 2001). Gender stereotypes are shared by both men and women (see, Johnson \& Tassinary, 2007). It is thus possible that everyone intuitively considers women as more social and communicative than men.

As stated in the introduction, the target of pointing took the status of a non-communicative object, and pointing to others' body parts requires processing them as objects. In heterotopagnosia, patients cannot point to others' body parts presumably because the ability to process a human body part as an object is impaired (Cleret de Langavant et al., 2009). This cognitive process is substantiated in healthy participants, as evidenced by slower reaction times for pointing to body parts than for pointing to 
objects (Cleret de Langavant et al., 2012). Since women are perceived as more socially engaged than men, processing women body parts as objects in the context of pointing can be more difficult than processing men's body parts as objects.

Here, we showed that the gender of the target impacts participants' pointing performance both in a heterotopagnosic patient (F.A.R.) and in healthy participants. Even if this gender effect would need to be replicated in other cultural contexts to be sure of its validity, the use of pointing towards somebody else can be a useful tool for investigating the mechanisms of social interaction.

\section{Notes}

1. According to our proposal, processing a human as an object only entails considering him or her as deprived of communicative abilities. This differs from the sexual objectification theory proposed to explain gender inequality, in which women are seen as tools on which one can act upon while denying their humanity (Fredrickson \& Roberts, 1997; Nussbaum, 1995).

2. Heterotopagnosic patients perform accurately when pointing to their own body parts. However, there is a lot of evidence that processing the self and the others involves distinct neural processes, and patients can show selective pointing impairment for either their own body parts or others' body parts (Felician et al., 2003; Hodzic, Muckli, Singer, \& Stirn, 2009).

\section{Acknowledgments}

The authors thank Alejandrina Cristia and Page Piccinini for the editing of this manuscript.

\section{Disclosure statement}

No potential conflict of interest was reported by the authors.

\section{Funding}

AQ2 The project was supported by a SOCODEV grant [grant number

1 ANR-09-BLAN-0327] awarded to E.D.; L.C.L. was supported by an APHP-CANAM grant; and A.C.B.L. was supported by a Contrat interface INSERM. This work was supported by [grant

AQ9 number ANR-10-LABX-0087-IEC], [grant number ANR-10-IDEXAQ10 AQ3 0001-02-PSL].

\section{References}

Agniel, A., Joanette, Y., Doyon, B., \& Duchein, C. (1993). PEGV et AQ4 PEGA. Isbergues: Ortho.
Auclair, L., Noulhiane, M., Raibaut, P., \& Amarenco, G. (2009). Where are your body parts? A pure case of heterotopagnosia following left parietal stroke. Neurocase, 15(6), 1-7.

Barbeau, E., Didic, M., Tramoni, E., Felician, O., Joubert, S., Sontheimer, A., ... Poncet, M. (2004). Evaluation of visual recognition memory in $\mathrm{MCl}$ patients. Neurology, 62(8), 13171322.

Baron-Cohen, S. (2005). The empathizing system: A revision of the 1994 model of the mindreading system. In B. B. Ellis, \& D. F. Bjorklund (Eds.), Origins of the social mind. New York: Guilford.

Brody, L. R., \& Hall, J. A. (2000). Gender, emotion, and expression. In M. Lewis, \& J. M. Haviland-Jones (Eds.), Handbook of emotions (pp. 338-349). New York: Guilford Press.

Charman, T. (2003). Why is joint attention a pivotal skill in autism? Philos Trans R Soc Lond B Biol Sci, 358(1430), 315-324. Cleret de Langavant, L., Trinkler, I., Cesaro, P., \& Bachoud-Levi, A.-C. (2009). Heterotopagnosia: When I point at parts of your body. Neuropsychologia, 47(7), 1745-1755.

Cleret de Langavant, L., Trinkler, I., Remy, P., Thirioux, B., Mclntyre, J., Berthoz, A., ... Bachoud-Lévi, A.-C. (2012). Viewing another person's body as a target object: a behavioural and PET study of pointing. Neuropsychologia, 50(8), 1801-1813.

Cleret de Langavant, L., Remy, P., Trinkler, I., Mclntyre, J., Dupoux, E., Berthoz, A., \& Bachoud-Lévi, A.-C. (2011). Behavioral and Neural Correlates of Communication via Pointing. Plos ONE, 6(3), e17719. doi:10.1371/journal.pone. 0017719

De Renzi, E., \& Faglioni, P. (1987). Normative data and screening power of a shortened version of the Token Test. Cortex, 14(1), 41-49.

Degos, J.-D., \& Bachoud-Lévi, A.-C. (1998). La désignation et son objet: pour une neuropsychologie de l'objectivation. Revue Neurologique, 154(4), 283-290.

Degos, J.-D., Bachoud-Lévi, A.-C., Ergis, A.-M., Pétrissans, C., \& Cesaro, P. (1997). Selective inability to point to extrapersonal targets after left posterior parietal lesions. Neurocase, 3(1), 31-39.

Deloche, G., Hannequin, D., Dordain, M., Perrier, D., Pichard, B., Quint, S., ... Cardebat, D. (1996). Confrontation oral naming: Performance differences between aphasics and normals. Brain and Language, 53(1), 105-120. doi:10.1006/ brln.1996.0039

Dubois, B., Slachevsky, A., Litvan, I., \& Pillon, B. (2000). The FAB A frontal assessment battery at bedside. Neurology, 55(11), 1621-1626.

Dubois, B., Touchon, J., Ousset, P., Vellas, B., \& Michel, B. (2002). "Les 5 mots", épreuve simple et sensible pour le diagnostic de la maladie d'Alzheimer. La presse médicale, 31, 16961699.

Ellis, L. (2011). Identifying and explaining apparent universal sex differences in cognition and behavior. Personality and Individual Differences, 51(5), 552-561.

Farris, C., Treat, T. A., Viken, R. J., \& McFall, R. M. (2008). Perceptual mechanisms that characterize gender differences 


\section{AQ7 198.}

L Fredrickson, B., \& Roberts, T. (1997). Toward Understanding

in decoding women's sexual intent. Psychol Sci., 19(4), 348354.

Felician, O., Ceccaldi, M., Didic, M., Thinus-Blanc, C., \& Poncet, M. (2003). Pointing to body parts: a double dissociation study. Neuropsychologia, 41(10), 1307-1316.

Folstein, M., Folstein, S., \& McHugh, P. "Mini Mental State": A practical method for grading the cognitive state of patients for the clinician. Journal of Psychiatric Research, 12(3), 189Women's Lived Experiences and Mental Health Risks. Psychology of Women Quarterly, 21(2), 173-206.

Gallace, A., \& Spence, C. (2010). The science of interpersonal touch: An overview. Neuroscience and Biobehavioral Reviews, 34(2), 246-259. doi:10.1016/j.neubiorev.2008.10.004

Goodglass, H., \& Kaplan, E. (1983). Boston naming Test. Philadelphia: Lea \& Febiger.

Gorno-Tempini, M., Brambati, S., Ginex, V., Ogar, J., Dronkers, N., Marcone, A., ... Miller, B. (2008). The logopenic/phonological variant of primary progressive aphasia. Neurology, 71 (16), 1227-1234. doi:10.1212/01.wnl.0000320506.79811.da

Heilman, M. (2001). Description and prescription: How gender stereotypes prevent women's ascent up the organizational ladder. Journal of Social Issues 57(4), 657-674.

Hodzic, A., Muckli, L., Singer, W., \& Stirn, A. (2009). Cortical responses to self and others. Hum Brain Mapp, 30(3), 951962. doi:10.1002/hbm.20558

Hofer, A., Siedentopf, C. M., Ischebeck, A., Rettenbacher, M. A., Verius, M., Felber, S., \& Fleischhacker, W. W. (2006). Gender differences in regional cerebral activity during the perception of emotion: A functional MRI study. Neuroimage, 32(2), 854-862. doi:10.1016/j.neuroimage. 2006.03.053

Jacquemot, C., Dupoux, E., Robotham, L., \& Bachoud-Levi, A. C. (2012). Specificity in rehabilitation of word production: a meta-analysis and a case study. Behav Neurol, 25(2), 73101. doi: 10.3233/BEN-2012-0358

Johnson, K. L., \& Tassinary, L. G. (2007). Compatibility of basic social perceptions determines perceived attractiveness. Proceedings of the National Academy of Sciences of the United States of America, 104(12), 5246-5251. doi:10.1073/ pnas.0608181104

Kita, S. (Ed.). (2003). Pointing: Where Language, Culture, and Cognition Meet. Mahwaj, NJ: Lawrence Erlbaum Associates.

Kret, M., \& De Gelder, B. (2012). A review on sex differences in processing emotional signals. Neuropsychologia, 50(7), 1211-1221.

Luria, A. (1965). Two Kinds of Motor Perseveration in Massive Injury of the Frontal Lobes. Brain, 88(1), 1-10.
Mattis, S. (1976). Mental status examination for organic mental syndrome in the elderly patient. New York: Grune \& Stratton.

Montagne, B., Kessels, R. P., Frigerio, E., de Haan, E. H., \& Perrett, D. I. (2005). Sex differences in the perception of affective facial expressions: do men really lack emotional sensitivity? Cogn Process, 6(2), 136-141.

Nussbaum, M. (1995). Objectification. Phiosophy and Public Affairs, 24, 249-291.

Pallier, C., Dupoux, E., \& Jeannin, X. (1997). EXPE: an expandable programming language for on-line psychological experiments. Behavion Research Methods, Instruments, and Computers, 29(3), 322-327.

Pavlova, M. (2009). Perception and understanding of intentions and actions: does gender matter? Neurosci Lett, 449(2), 133136.

Proverbio, A. M., Adorni, R., Zani, A., \& Trestianu, L. (2009). Sex differences in the brain response to affective scenes with or without humans. Neuropsychologia, 47(12), 2374-2388.

Reitan, R. (1955). The relation of the trail making test to organic brain damage. Journal of Consulting and Clinical Psychology, 19(5), 393-394.

Signoret, J., Bonvarlet, M., Benoit, N., Bolgert, F., Eustache, F., \& Leger, J. (1988). Batterie d'évaluation des états démentiels; description et validation. La maladie d'Alzheimer et ses limites Congrès de Psychiatrie et de Neurologie de Langue Française (pp. 265-270). Paris: Masson.

Singer, T., Seymour, B., O'Doherty, J. P., Stephan, K. E., Dolan, R. J., \& Frith, C. D. (2006). Empathic neural responses are modulated by the perceived fairness of others. Nature, 439(7075), 466-469.

Snodgrass, J. G., \& Vanderwart, M. (1980). Standardized Set of 260 Pictures - Norms for Name Agreement, Image Agreement, Familiarity, and Visual Complexity. Journal of Experimental Psychology-Human Learning and Memory, 6(2), 174-215. doi:10.1037/0278-7393.6.2.174

Tallis, R. (2010). Michelangelo's Finger. An exploration of everyday transcendence. New Have: Yale University Press.

Tomasello, M., Carpenter, M., Call, J., Behne, T., \& Moll, H. (2005). Understanding and sharing intentions: the origins of cultural cognition. Behav Brain Sci., 28(5), 675-691; discussion 691735

Unger, R., \& Crawford, M. (1993). Sex and gender - The troubled relationship between terms and concepts. Psychological Science, 4(2), 122-124.

Wechsler, D. (1981). Wechsler Adult Intelligence Scale-revised manual. New York: Psychological Corporation.

Wood, W., \& Eagly, A. H. (2002). A cross-cultural analysis of the behavior of women and men: implications for the origins of sex differences. Psychol Bull., 128(5), 699-727. 